\title{
O Desenvolvimento Profissional do Professor de Matemática para Promover o Raciocínio Matemático
}

\author{
Flavia Sueli Fabiani Marcatto ${ }^{1}$ i \\ Universidade Federal de Itajubá (UNIFEI), \\ Instituto de Matemática e Computação, Itajubá, MG, Brasil
}

\begin{abstract}
Resumo
Este artigo apresenta resultados de uma investigação sobre raciocínio matemático, de cunho qualitativo com uma abordagem de Instrução Baseada em Design (IBD), a partir de tarefas de exploração com o objetivo de identificar, e documentar processos de raciocínio. A experiência envolveu futuros professores de matemática, cursando horas de Prática como Componente Curricular (PCC) e bolsistas do Programa Institucional de Iniciação à Docência (Pibid). Destacamos, o papel que as representações matemáticas desempenham, na compreensão, organização e planejamento de sequências instrucionais. Os resultados evidenciam a importância do trabalho com tarefas exploratórias, que propõe uma inovação na dinâmica da sala de aula, dando protagonismo aos alunos, bem como desenvolveram o raciocínio matemático indutivo baseado na identificação de padrões e o dedutivo baseado em definições e propriedades matemáticas utilizando representação algébrica para formularem conjecturas.
\end{abstract}

Palavras-chave: Tarefas Exploratórias; Instrução Baseada em Design; Formação de Professores de Matemática.

\section{The Professional Development of the Mathematics Teacher to Promote Mathematical Reasoning}

\begin{abstract}
This article presents the results of an investigation on mathematical reasoning, of a qualitative nature with a Design Based Instruction (IBD) approach, from exploration tasks with the objective of identifying and documenting reasoning processes. The experience involved future mathematics teachers, studying hours of Practice as a Curriculum Component (PCC) and scholarship holders of the Institutional Program for Initiation to Teaching (Pibid). We highlight the role that mathematical representations play in understanding, organizing and planning instructional sequences. The results highlight the importance of working with exploratory tasks, which proposes an innovation in the dynamics of the classroom, giving protagonism to students, as well as developing inductive
\end{abstract}

Submetido em: 03/02/2021

Aceito em: 28/02/2021

Publicado em: 14/03/2021

${ }^{1}$ Doutora em Educação Matemática pela UNESP-Rio Claro. Pesquisadora do GTERP- PPGEM - UNESP-Rio Claro.

E-mail: flaviamarcatto@unifei.edu.br. 
mathematical reasoning based on the identification of patterns and the deductive based on definitions and mathematical properties using algebraic representation to formulate conjectures.

Keywords: Exploratory Tasks; Design Based Instruction; Teacher Training.

\title{
El Desarrollo Profesional del Profesor de Matemáticas para Promover el Raciocinio Matemático
}

\begin{abstract}
Resumen
Este artículo presenta los resultados de una investigación cualitativa sobre el raciocinio matemático con un enfoque de Instrucción Basada en el Diseño (IBD), a partir de tareas de exploración con el objetivo de identificar y documentar los procesos de razonamiento. En la experiencia participaron futuros profesores de matemáticas, cursando horas de Práctica como Componente Curricular (PCC) y becarios del Programa Institucional de Iniciación a la Docencia (Pibid). Destacamos el papel que desempeñan las representaciones matemáticas en la comprensión, la organización y la planificación de las secuencias didácticas. Los resultados destacan la importancia de trabajar con tareas exploratorias, lo que propone una innovación en la dinámica del aula, dando protagonismo a los alumnos, así como desarrollar el razonamiento matemático inductivo basado en la identificación de patrones y el deductivo basado en definiciones y propiedades matemáticas utilizando la representación algebraica para formular conjeturas.
\end{abstract}

Palabras clave: Tareas de Exploración; Instrucción Basada en el Diseño; Formación de profesores de matemáticas.

\section{Introdução}

Para desenvolver o aprendizado em Matemática, uma disciplina de conteúdo escolar e um conjunto de práticas culturais de reconhecida importância, onde os alunos devem ser capazes de raciocinar matematicamente com fluência. Ao levá-los a desenvolver esta habilidade, os professores precisam compreender a natureza do raciocínio matemático e serem capazes de usar estratégias de ensino que o promovam nos alunos. Diante disso é importante proporcionar aos alunos a oportunidade de trabalhar em tarefas matemáticas que exigem raciocínio e, ao mesmo tempo, estimulam o seu desenvolvimento, bem como a reflexão sobre os raciocínios realizados.

De acordo com Stylianides e Harel (2018), existe um reconhecimento internacional da importância do desenvolvimento de estudos sobre raciocínio, argumentação e prova na aprendizagem de matemática em todos os níveis de ensino: fundamental, médio e superior, em especial na formação inicial de professores de matemática. Os processos de raciocínio matemático não são tratados de forma explícita na maioria das salas de aula nos cursos de formação de professores.

É importante reconhecer a necessidade de um trabalho de formação que favoreça os futuros professores a desenvolver o conhecimento e a habilidade de promover o raciocínio matemático dos seus alunos. Deste modo, o objetivo deste trabalho foi investigar e documentar os processos de 
raciocínio em candidatos a professores e desenvolver o conhecimento matemático e didático que os professores precisam para conduzir uma prática que promova o raciocínio matemático dos alunos e indicar evidências, alcançadas por meio da Instrução Baseada em Design (IBD) para apoiar o seu desenvolvimento em futuros professores de matemática, dos anos finais do Ensino Fundamental e do Ensino Médio. O objetivo complementar, foi explorar a implementação das Tarefas de Exploração e Desenvolvimento da Aprendizagem e do Ensino (TEDAE), como forma de promover o raciocínio, através da IBD, nas horas de Prática como Componente Curricular (PCC), para permitir reflexões de como foi realizada, os meios projetados para apoiá-lo para aqueles que desejam adaptá-los em seus contextos.

Primeiro descrevo o contexto em que este trabalho se desenvolveu na perspectiva da Educação Matemática, as horas de PCC, que se constituem facilitadoras do autêntico desenvolvimento profissional (MARCATTO, 2012), obrigatória nos currículos dos cursos de Licenciatura em Matemática, a participação de alunos matriculados nas disciplinas que envolvem as horas de PCC, durante a primeira metade do curso e que também eram bolsistas do Programa Institucional de Iniciação à Docência (Pibid). Na sequência faço uma revisão de literatura que serviu de base para conduzirmos esta experiência, sobre os processos de raciocínio matemático, em seguida forneço a descrição do percurso metodológico, para relatar os achados desta investigação.

Concluo que as TEDAE foram importantes no maior envolvimento e protagonismo dos alunos com as atividades matemáticas, o que favoreceu a documentação dos processos de raciocínio. Observou-se que os alunos usam com frequência, o raciocínio indutivo baseado na identificação de padrões através da observação de dados ou construindo os seus próprios esquemas visuais ou numéricos. Também foi observado o raciocínio dedutivo baseado em definições e propriedades matemáticas utilizando representação algébrica para formularem conjecturas. Neste caso, a representação algébrica é usada como ferramenta de exploração e de apresentação de conjecturas e justificações formais.

\section{Enquadramento teórico}

\subsection{Porque as horas de Prática como componente curricular, para o desenvolvimento desta proposta?}

O ensino e a aprendizagem profissional dos professores de matemática estão em muitos cursos de Licenciatura em Matemática, no Brasil, ancorados nas horas de PCC, que neste texto serão referenciadas como - núcleo das horas de prática - que se constituem como facilitadoras do autêntico desenvolvimento profissional. (MARCATTO, 2012) 
Para Gatti (2017), existem vários problemas nos currículos de formação de professores, entre eles o pequeno espaço concedido aos estudos de didática, das metodologias e práticas de ensino e a falta de articulação destes com outros conteúdos do curso. A Resolução CNE/CP n. 2/2015 defende a articulação entre a teoria e a prática no processo de formação docente de modo a propiciar a formação teórica, de conteúdos e pedagógica, relacionando teoria à prática, contribuindo para o exercício profissional dos futuros professores. É importante lembrar que as normativas não são atuantes, dependem de ações efetivas que propiciem a passagem do dito ao realizado e, de cada instituição, bem como dos seus docentes, em relação às proposições postas pelos documentos normativos e orientadores.

A integração dos conteúdos curriculares, sejam estes conceituais, processuais ou atitudinais, devem se estruturar em uma organização coerente dos vários saberes que integram o conhecimento profissional, da competência do futuro profissional de ensinar, ou seja, fazer alguém aprender; eles devem estar preparados para interpretar o sentido de cada situação e responder de forma didaticamente adequada ao modo de aprender de cada aluno; da mobilização informada dos vários tipos de conhecimento necessários ao saber agir do professor em cada situação. (ROLDÃO, 2017)

Em estudos anteriores Marcatto $(2012,2019)$ apontam que prática é mais que praticar, tão pouco é o momento de aplicação da teoria ou menos ainda concretizar, em seu domínio, o conhecimento teórico. A prática de ensino é o momento de favorecer o protagonismo do aluno, de modo a desenvolver o patrimônio de ideias que esses trazem consigo articulando-as com conceitos e ideias do conteúdo. É compreender as necessidades de conhecimento do ato e no ato de ensinar, revezando e articulando conhecimentos, considerando e desenvolvendo o patrimônio de ideias que os estudantes trazem consigo, incluindo aspectos sociopolíticos, e dessa forma gerando novos tipos ou tipos suplementares derivados do conhecimento formal, tendo como referência o mesmo padrão epistemológico.

Para Ball e Cohen (1999), a formação de professores necessita se tornar suficiente para imunizar professores contra práticas conservadoras, como a tradição matemática escolar (SKOVSMOSE e PENTEADO, 2016) que muitos professores acreditam que seja o único caminho para ensinar matemática, que aprendem pelo acúmulo de experiência, quando chegam a escola de educação básica. Os professores precisam compreender o conteúdo que ensinam de modo diferente do que aprenderam quando eram alunos. Por exemplo, eles precisam dar significados, conhecer conceitos e estabelecer conexões entre eles e não apenas prover informação e cobrar a realização de procedimentos. Necessitam ainda, enxergar maneiras pelas quais ideias conectam-se entre conteúdos, e com a vida cotidiana, para que assim possam selecionar e utilizar apropriadamente atividades de investigação, nos contextos adequados. 
Os professores de futuros professores de matemática têm um papel central e crítico na geração de conhecimento. A ideia não é desenvolver um conhecimento que em certo sentido eles já conhecem, seja o 'conhecimento para a prática' ou o 'conhecimento em prática' e sim, o 'conhecimento da prática' que visa construir um conhecimento significativo, onde a investigação e a exploração são reconhecidas como um esforço de transformar o ensino e a aprendizagem, sem haver, portanto, dissociação entre a teoria e a prática. (COCHRAN e SMITH-LITLE, 1999)

O objetivo é compreender mais de perto as relações entre prática e conhecimento, bem como o processo de produção de conhecimento por meio da exploração, da investigação, a relação entre investigação e prática e o que os professores aprendem com a investigação, permitindo o necessário movimento na formação inicial que envolve o professor da universidade, o licenciando e o professor da escola e a educação básica. Ainda Ball e Cohen (1999), destacam em seus estudos, o valor do uso de ferramentas de aprendizagem, como as tarefas instrucionais, para fundamentar o desenvolvimento profissional na prática educacional em sala de aula.

\subsection{Tarefas de exploração e desenvolvimento da aprendizagem e do ensino}

As tarefas instrucionais, são ferramentas de mediação que um professor usa para propor matemática e seguir interativamente com os estudantes, objetivando a aprendizagem profissional, em outras palavras, materiais que são usados instrumentalmente para atingir uma meta ou propósito, em eventos de aprendizagem que se referem a sessões de desenvolvimento profissional programadas que podem dar origem a oportunidades de aprendizagem e desenvolvimento. (COOB e JACKON, 2012)

Essas tarefas têm como características o elevado desafio cognitivo, incluem necessariamente o trabalho escrito dos alunos e/ou a gravação das atividades da sala de aula, e envolve ambientes onde possam reorganizar e construir, dessa forma evoluir para entendimentos matemáticos e raciocínios cada vez mais sofisticados com o apoio do professor.

Neste estudo, as tarefas instrucionais serão nomeadas como Tarefas de Exploração e Desenvolvimento da Aprendizagem e do Ensino (TEDAE). O objetivo das TEDAE como mediadoras da aprendizagem, nas horas de PCC é promover o desenvolvimento do aprendizado 'da prática', apoiados pela IBD, com foco nos processos de aprendizagem, e ter como pano de fundo teorias que articulem um papel ativo dos alunos, com apoio dos professores na construção de seus próprios conhecimentos. (PREDINGER, GRAVEMEIJER, CONFREY, 2015)

A premissa da TEDAE é projetar e criar ambientes de aprendizagem, onde os alunos recebem tarefas desafiadoras para trabalhar e amplas oportunidades para participar individual e coletivamente das discussões, e atendidas estas condições o foco é a emergência de pensamento do aluno procurando 
identificar momentos produtivos ou de falha, ao longo do tempo sempre com apoio do professor/investigador.

Estudos realizados pelo Grupo de Investigação da Didática da Matemática, do Instituto de Educação da Universidade de Lisboa-PT, acrescentaram descobertas importantes sobre práticas em sala de aula que estimulam o raciocínio dos alunos. (HENRIQUES, 2011; PONTE, MATAPEREIRA e HENRIQUES 2012; PONTE e QUARESMA, 2014)

Essas pesquisas mostraram que o uso de tarefas exploratórias e de investigação associados a pesquisas de Design com foco nos processos de aprendizagem favorecem o estabelecimento de um ambiente de sala de aula que incentive os alunos à apresentação de suas estratégias, justificativas e o debate coletivo pode levar a desenvolver o hábito de justificar afirmações matemáticas usando representações, propriedades e definições. Os autores concordam que o trabalho com tarefas adequadas em sala de aula, podem desenvolver nos alunos a capacidade de usar o raciocínio indutivo e abdutivo com objetos matemáticos e suas representações para produzir conjecturas e generalizações, e usar o raciocínio dedutivo com base em definições, representações e propriedades matemáticas para produzir justificativas.

Assim, a experiência adquirida com tais estudos levou ao desenvolvimento de uma abordagem específica para a formação de professores de matemática (PONTE, MATA- PEREIRA E QUARESMA, 2013) que enfatiza uma orientação para as práticas de sala de aula, com foco na aprendizagem dos alunos e imersão na cultura profissional. (PONTE et al, 2012)

Para ser eficaz, o desenvolvimento profissional deve ter efeitos na prática profissional dos professores e, portanto, atividades de desenvolvimento profissional precisam oferecer aos professores oportunidades para experimentar novas formas de ensino. A educação de futuros professores de matemática apresenta desafios enfrentados ao colocar em prática o conhecimento que eles desenvolveram, em programas de formação (PONTE E CHAPMAN, 2016), bem como na implementação de um ensino inovador de matemática de acordo com as atuais orientações curriculares (NCTM, 2000; BNCC, 2017) que enfatizam o raciocínio.

\subsection{Tarefas para o desenvolvimento do raciocínio}

Para Ponte (2005), quando um aluno dispõe de um processo imediato para resolver uma atividade que foi proposta, essa se constitui um exercício. Por outro lado, quando o aluno não dispõe de um processo imediato, um caminho definido para resolver a questão, nesse caso se constitui em um problema. O problema é uma tarefa de estrutura fechada onde está claro para o aluno o que é pedido e o que é dado, no entanto, com elevado nível de desafio, pois o aluno desconhece, a princípio, o procedimento que deve adotar. 
Raciocinar é realizar inferências e estabelecer conclusões a partir de fatos conhecidos ou assumidos como verdadeiros de forma fundamentada, em outras palavras, a partir de informação fornecida, obter nova informação através de um processo justificado. O raciocínio matemático pode ser visto como um conjunto de processos mentais complexos (OLIVEIRA, 2008), através dos quais se obtêm novas proposições, tendo como ponto de partida proposições já conhecidas. Nesta perspectiva, o raciocínio matemático envolve dois momentos: obter informação e a partir de informação existente validá-la por meio de justificações fundamentadas, dessa forma construindo conhecimento matemático. Para Ponte, Mata-Pereira, Henriques (2012) os processos de raciocínio envolvem a formulação de questões, conjecturas, teste de conjecturas e a realização de justificações. As questões e as conjecturas podem ser gerais ou específicas. Um importante processo de raciocínio é a generalização, que parte de uma conclusão ou conjectura específicas para formular uma conjectura geral. Ainda, para esses autores, raciocinar matematicamente é fazer inferências de forma justificada, seja indutiva, abdutiva ou dedutivamente.

O raciocínio dedutivo, característico da matemática formal, tem relação com a demonstração, onde demonstrar envolve encadear asserções de forma lógica e justificada. Desde que a cadeia de deduções não contenha erros, o raciocínio dedutivo produz conclusões válidas. Se desenvolve do geral para o particular, com uma conclusão necessária que pode validar ou refutar algo. Esta inferência tem uma relação necessária entre a premissa e a conclusão, aonde uma conclusão vem necessariamente de um conjunto de premissas e deve ser desenvolvida, valorizando as suas configurações informais. (MATA-PEREIRA e PONTE, 2012)

O raciocínio indutivo desenvolve-se a partir de observações que acontecem com a exploração de conceitos e ideias matemáticas a um nível prático e intuitivo. Desenvolve-se do particular para o geral e tem papel significativo na formação de conhecimento, no entanto, sem conduzir a conclusões necessárias. Acontece quando se fazem previsões, possibilita desenvolver conjecturas e generalizações que podem posteriormente ser verificadas por processos de demonstração eminentemente dedutivos como a indução matemática. (MATA-PEREIRA e PONTE, 2012; OLIVEIRA 2002) O raciocínio abdutivo tem características explicativas, e possui também perspectivas de construção de conhecimento, é utilizado para explicar algo com conclusões plausíveis no contexto da situação em questão. (MATA-PEREIRA e PONTE, 2012)

O modelo de raciocínio matemático concebido neste artigo é o de Mata-Pereira e Ponte (2012) que procura enquadrar o raciocínio matemático dos alunos em processos fundamentais, de representar e dar significado. O raciocínio matemático apoia-se em representações sejam elas ativas: uso de materiais manipuláveis ou ações como contar, usando os dedos; icónicas: imagens, figuras e 
diagramas; ou simbólicas: símbolos matemáticos ou outros símbolos e linguagem natural; e requer ainda, a atribuição de significados aos objetos e ações envolvidas.

Esse modelo se apoia no processo de realização de uma investigação matemática ou a resolução de um problema matemático, começando pela formulação de questões, passando para a formulação de conjecturas e estratégias de resolução, que podem ou não envolver generalização, aplicando essas estratégias e testando as conjecturas, até o processo de validação que ocorre por meio da justificação. A generalização e a justificação se destacam como aspectos essenciais do raciocínio matemático. As representações do raciocínio matemático dos alunos podem ser comunicadas por escrito ou de forma oral.

Processos de formação devem integrar as TEDAE que explorem processos de raciocínio que incluem a formulação de questões, formulação e teste de conjecturas e a realização de justificações. Formular uma generalização a partir da identificação de uma certa característica comum a diversos casos como resultado do campo indutivo ou estabelecendo uma relação entre diversos aspectos de certa situação no campo abdutivo, deve ser provada por meio do raciocínio dedutivo, para ser aceita como resultado matemático.

\section{Metodologia da pesquisa}

\subsection{Contexto do estudo e os participantes da pesquisa}

O processo formativo em que foram recolhidos os dados foi desenvolvido ao longo de cinco encontros de três horas cada e tinha por objetivo apoiar o desenvolvimento de práticas instrucionais para candidatos a professores de matemática, com atividades de exploração que envolveram diagnosticar e documentar o raciocínio dos alunos.

Participaram deste estudo, oito licenciandos em matemática, todos matriculados em disciplinas do núcleo das horas de PCC e bolsistas do Pibid. Os encontros contemplaram momentos de estudos teóricos (totalizando 3 horas) e momentos de trabalho mediados pelas TEDAE elaboradas pela formadora responsável dos encontros (no total de 12h). O processo formativo continha duas TEDAE, intituladas: tarefa diagnóstica (Adicionando Hexágonos) e tarefa de formação (Comparando Triângulos), desenvolvidas em momentos distintos, totalizando $15 \mathrm{~h}$. O registro das atividades propostas foi realizado através de entrega da resolução das atividades por escrito e gravações de vídeo em sala de aula.

Foram definidas as seguintes normas para os participantes do estudo, durante a fase de intervenção com as TEDAE: os alunos foram orientados a explicar e justificar seu raciocínio; a ouvir e tentar entender as explicações dos outros; a indicar o seu não entendimento, diante da exposição 
dos colegas e, se possível, a colocar questões para o esclarecimento; e a indicar quando consideravam as soluções inválidas e expor para o grupo as razões do seu julgamento.

Os encontros foram dinamizados de forma a conciliar momentos de trabalhos (i) individuais, (ii) em pequenos grupos e (iii) em discussões coletivas. Os participantes eram futuros professores de matemática do ensino fundamental e médio, bolsistas do programa Pibid.

O Pibid é uma política de formação de professores que tem como fundamento viabilizar a inserção de candidatos a professor no contexto do mundo de trabalho, com condições de apoiar o aprender a ensinar os estudantes para o século XXI. Enquanto política educacional, o programa tem características que possibilitam produzir efeitos nas práticas dos participantes e consequentemente promover mudanças no ensino e na aprendizagem pois permite problematizar o contexto no qual estão inseridos, o seu próprio conhecimento e o conhecimento de outros professores envolvidos nos processos de formação sejam no Ensino Superior ou na Educação Básica.

\subsection{Método de pesquisa, recolha e organização de dados}

Para desenvolver uma prática (no sentido de ação) promotora do raciocínio matemático dos alunos, foi necessário compreender os processos de raciocínio matemático. Este estudo tem cunho qualitativo e interpretativo. Qualitativo porque valoriza processos didáticos em ambiente natural (BOGDAN; BIKLEN, 1994) e interpretativo quando procura compreender, no contexto do ensino, os modos pelos quais professores e alunos constituem ambientes uns para os outros (ERICKSON, 1986). Este estudo se apoia em um experimento de design (COBB, CONFREY, DISESSA, LEHRER, \& SCHAUBLE, 2003); que aqui identificarei por Instrução Baseada em Design - IBD (MATAPEREIRA E PONTE, 2018) preservando as características propostas por Cobb et al (2003).

Para Cobb et al (2003) os experimentos baseados em design promovem uma maior compreensão da 'ecologia da aprendizagem', que definem como um sistema complexo, interativo, que envolve múltiplos elementos de diferentes tipos e níveis, que projeta seus elementos e antecipa como estes interagem para apoiar o aprendizado. Elementos de uma 'ecologia da aprendizagem' incluem as tarefas exploratórias propostas aos alunos para que resolvam, as normas de participação estabelecidas em sala de aula, os tipos de discurso que são encorajados, o ambiente de investigação que se estabelece na sala de aula, as ferramentas e meios materiais fornecidos, e os meios práticos pelos quais se orquestrou as relações entre esses elementos. A ecologia de aprendizagem é conceituada como sistemas em interação e não como uma coleção de atividades ou uma lista de fatores que influenciam a aprendizagem.

A IBD se constitui em um processo de pesquisa que envolve a pessoa que conhece (a pesquisadora em questão), o contexto em causa (a sala de aula da prática de ensino na formação de 
professores (FP) de matemática) e a atividade que participa (o experimento de design), tendo como objetivo principal estudar processos de aprendizagem (raciocínio matemático) ou de mudança e a forma (tarefas exploratórias) de os promover em contextos naturais (FP de matemática). Dessa forma, justifica-se a escolha dessa metodologia.

As etapas desse estudo seguiram a orientação das fases de: preparação, intervenção e análise retrospectiva. Na fase inicial, preparação, buscou-se delimitar os objetivos para a aprendizagem dos futuros professores de matemática, realizou-se um estudo bibliográfico aprofundado sobre desenvolvimento do raciocínio matemático, documentou-se o ponto de partida dos participantes (tarefa diagnóstica), especificou-se o percurso de aprendizagem previsto e colocou-se o estudo num contexto teórico. $\mathrm{Na}$ etapa seguinte, realização, foi o momento da intervenção com futuros professores de matemática, realizando reflexões regulares, analisando e interpretando os registros, bem como planejando atividades futuras. Nesse momento, a pesquisadora recebeu a colaboração de grupos de alunos do Pibid.

A unidade de análise considerada, neste estudo, foram os episódios documentados em que o tema matemático foco da atividade e o discurso em sala de aula considerado relevante para o contexto do estudo. Nesse sentido os episódios críticos para a análise foram aqueles que apoiaram ou refutaram o paradigma inicial. Esses episódios podem não parecer importantes por si só, mas tornam-se críticos quando vistos em ordem cronológica com outros episódios.

Neste artigo, é apresentada uma análise geral de registros gerados pelas resoluções e sínteses reflexivas dos futuros professores ocorridas nos dois ciclos de Design. As duas TEDAE tinham a intenção de promover discussões matemáticas e didáticas acerca do raciocínio matemático. Cada uma destas TEDAE tinha o formato que a seguir se apresenta.

A primeira TEDAE, nomeada diagnóstica, teve como objetivo documentar os processos de raciocínio matemático apresentadas pelos futuros professores de matemática.

Figura 1: Tarefa diagnóstica

Considere a tarefa seguinte:

\section{Adicionando Hexágonos}

Cada figura no padrão abaixo é feita de hexágonos que medem 1 centímetro de cada lado. 


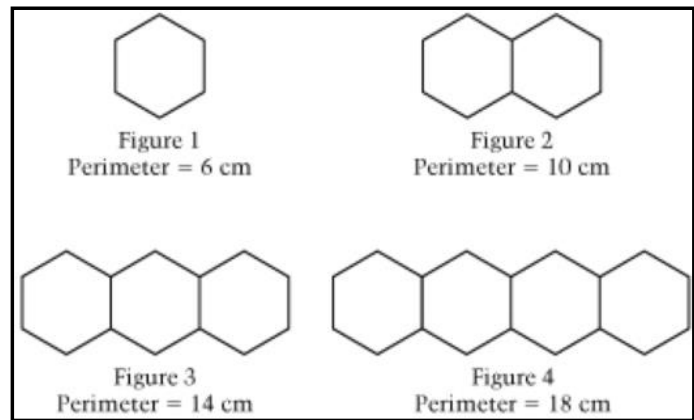

1. Desenhe e encontre o perímetro da Figura 5.

2. Se o padrão de adicionar um hexágono a cada figura continuar, qual será o perímetro da $25^{a}$. figura no padrão encontrado? Justifique sua resposta.

3. Extensão: Como você pode encontrar o perímetro de qualquer figura. (Uma figura com n hexágonos?)

Após resolver a Tarefa Hexágonos. Reflita e responda:

(Adaptado de Staples, M., 2014)

I.Que razões o levariam a aplicar essa tarefa na sua sala de aula? Em quais anos da Educação Básica aplicaria essa tarefa? Você faria alguma alteração?

II.Que dificuldades você pode prever que os alunos evidenciariam durante a resolução?

III.Quais conceitos e conteúdos matemáticos podem ser abordados por meio dessa tarefa?

Fonte: dados da pesquisa

\section{A 2a. TEDAE, tarefa de formação objetivou identificar, discutir e refletir sobre os processos} e dificuldades dos alunos, sobre o raciocínio matemático.

Figura 2: Tarefa de formação

1. Apresenta-se a seguir a seguinte tarefa:

\section{Comparando triângulos}

\section{Vamos comparar triângulos}

Em dois triângulos I e II a, b e c representam os comprimentos dos três lados do triângulo I e m, n, e p os comprimentos dos lados do triângulo II. Um colega diz que:

"Se $\mathrm{a}>\mathrm{m}, \mathrm{b}>\mathrm{n}$ e c $>$ p, então a área do triângulo I é maior do que a do triângulo II".

Eu respondi que ele tinha razão. Apresenta uma justificativa que mostre que a afirmação é verdadeira.

\subsection{Resolva a tarefa.}

1.2. Indique o(s) objetivo(s) de aprendizagem que consideraria para uma aula onde propusesse a tarefa acima apresentada, e indique algumas razões que fundamentem a escolha desse(s) objetivo(s).

1.3. Dê exemplos de resoluções da tarefa que espera que os seus alunos possam apresentar.

1.4. Enumere dificuldades que antecipa nos seus alunos ao realizarem a tarefa, isto é ao formularem justificações, e diga como procederia, em cada caso, para os apoiar.

2. Suponha agora que as resoluções da tarefa que a seguir se apresentam surgiram no momento de trabalho autónomo dos seus alunos.

Resolução R1: Se for $\mathrm{a}=\mathrm{b}=\mathrm{c}=2 \mathrm{e} \mathrm{m}=\mathrm{n}=\mathrm{q}=1$, então vê-se logo que o triângulo I é maior do que o triângulo II. Experimentei com outros casos como mostro na figura abaixo e a área do triângulo I é sempre maior do que o triângulo II. Assim, tenho a certeza que a afirmação é sempre verdadeira. 

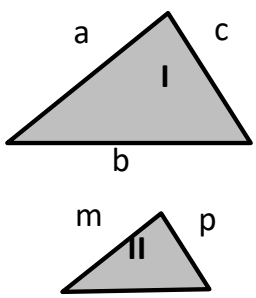

$\mathrm{n}$

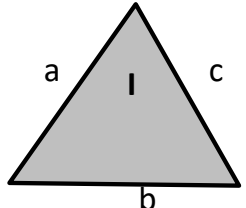

$\mathrm{n}$

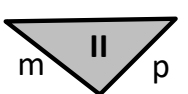

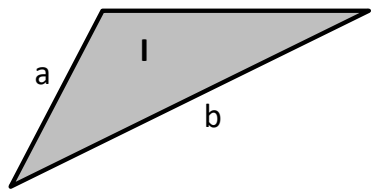

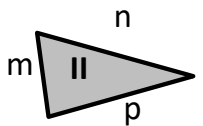

Resolução R2: Todos sabemos que a área de um triângulo é $1 \frac{1}{2}$ do produto da sua base pela altura. Como mostro na figura abaixo, a área do triângulo I é $\frac{b x h}{2} \mathrm{e}$ a área do triângulo II é $\frac{n x l}{2}$. Sabemos que $\mathrm{b}>\mathrm{n}$. Uma vez que $\mathrm{a}>\mathrm{m} \mathrm{e} \mathrm{c}>\mathrm{p}$, então tem de ser verdade que $\mathrm{h}>1$. Assim, $\frac{b x h}{2}$ é maior do que $\frac{n x l}{2}$. Portanto a área do triângulo I é maior do que a área do triângulo II.
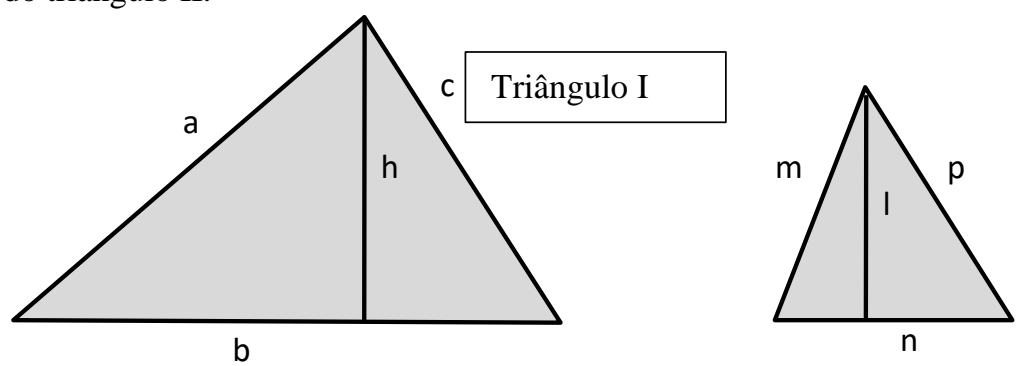

Triângulo II

Resolução R3: Como cada lado do triângulo II é menor do que o lado correspondente do triângulo I, o perímetro do triângulo I é maior do que o do triângulo II. Se usarmos fios para construir cada um dos triângulos, precisamos de um fio maior para o triângulo I do que para o triângulo II. Assim, a área do triângulo I é maior do que a área do triângulo II.

2.1. Analise cada uma das justificações apresentadas e indique se as aceitaria como válidas e porquê. Indique também em que se assemelham e distinguem os processos de raciocínio que identifica nas resoluções.

2.2. Supondo que estas três justificações surgiram no momento de trabalho autónomo dos alunos, apresente uma sequência por que optaria para as discutir, com seus alunos, no momento de discussão coletiva e razões que justifiquem a sua opção.

Fonte: dados da pesquisa

(Adaptado de Liu, 2013)

\section{Apresentação e análise dos dados}

As tarefas foram o ponto de partida para a identificação dos processos de raciocínio que os licenciandos utilizam ao realizarem atividades investigativas. Em um segundo momento, a 1a. TEDAE continha questões para os bolsistas refletirem, nos seguintes aspectos: (i) gestão da aula; (ii) possíveis dificuldades dos alunos da educação básica. A 2a. TEDAE, de formação, também questiona os mesmos aspectos da tarefa anterior e além de apresentar três resoluções possíveis, de alunos da educação básica. Em seguida, os futuros professores eram solicitados a analisar essas soluções e refletir sobre as ações dos professores, utilizando-as em sala de aula no momento da discussão coletiva.

Os candidatos a professor apresentaram dificuldades em gerenciar o tempo para resolver as tarefas. Utilizaram uma representação visual para a compreensão e o registro. As representações foram utilizadas para procurar regularidades e compreender propriedades importantes dos elementos da sequência. Por outro, foram usadas como ferramenta de registro de seus raciocínios durante a 
eISSN: $2526-9062$

exploração, permitindo-lhes focarem nos processos de raciocínio. Deste modo, as representações construídas facilitaram um processo indutivo de raciocínio que os conduziu à formulação das primeiras conjeturas.

Figura 3: Exemplos de resoluções dos bolsistas

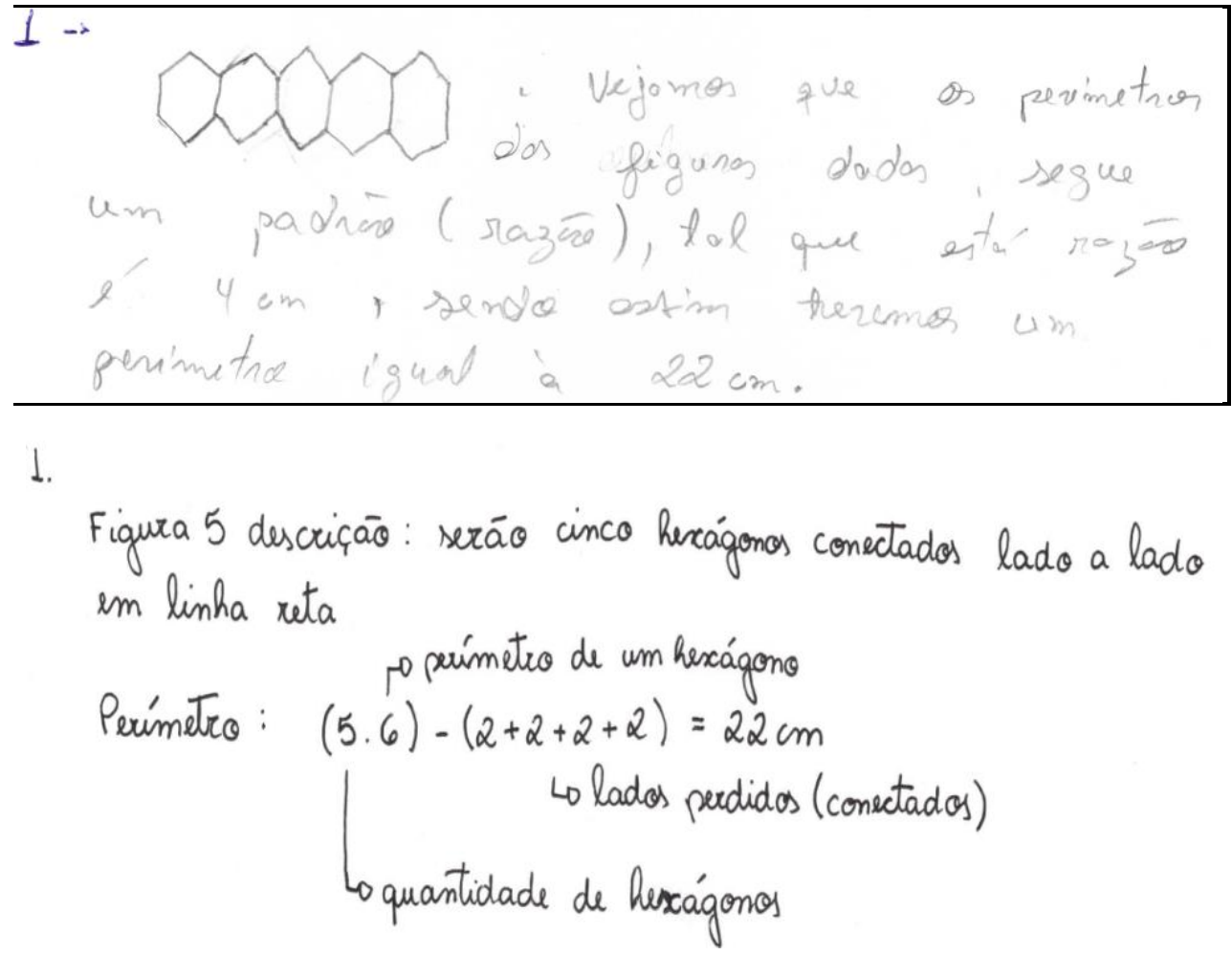

Fonte: dados da pesquisa

Os licenciandos também utilizam a linguagem natural para apresentarem os seus raciocínios e as suas conjecturas, como se observa na figura 3. Nessa TEDE, a utilização da linguagem natural foi articulada com a representação gráfica e pareceu facilitar a organização da informação de forma sequencial, preservando as relações temporais e lógicas, tal como eles a exploram.

Quando solicitados a generalizar as suas conjecturas, obtidas através de raciocínio indutivo, os bolsistas consideraram necessária uma formalização dos resultados usando tabelas e notação simbólica, mas continuaram recorrendo à linguagem natural. 
Figura 4: Exemplos de resoluções dos bolsistas
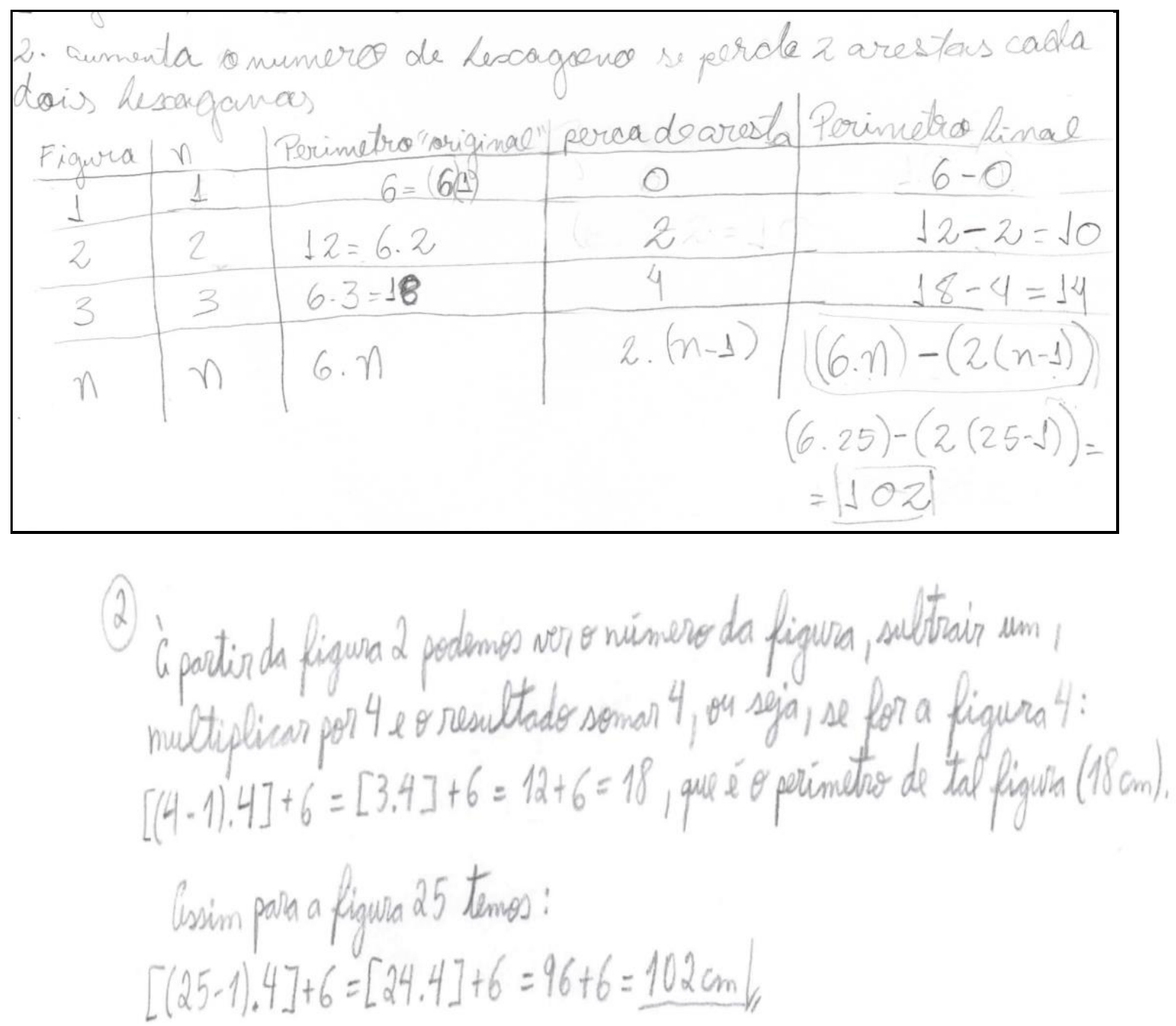

Fonte: dados da pesquisa

A combinação da linguagem natural com a algébrica parece ser benéfica para o uso do raciocínio dedutivo no processo de generalização e justificação formal de conjecturas.

Os licenciandos também utilizam a linguagem natural para apresentarem os seus raciocínios e as suas conjecturas. Para as duas TEDAEs, essa linguagem foi articulada com a representação gráfica e pareceu facilitar a organização da informação de forma sequencial, preservando as relações temporais e lógicas, tal como eles a exploram. A utilização de diferentes tipos de representação, geométrica, linguagem natural, algébrica e tabelar são frequentes nas soluções dos licenciandos.

Os futuros professores de matemática, parecem carecer de maturidade profissional necessária, não apenas no conhecimento de matemática e didática da matemática, mas também no que diz respeito ao seu desenvolvimento pessoal e social. Apresentando também, um conhecimento limitado sobre o currículo de matemática da educação básica, dos objetos de aprendizagem e dos modos de agir em situações de dificuldades dos alunos. 


\section{Considerações Finais}

Esse artigo apresenta os processos de raciocínio que bolsistas do Pibid utilizaram na realização de atividades de exploração, por meio das TEDAEs, em uma fase de diagnóstico da compreensão dos alunos e destaca o papel que as representações matemáticas desempenham, nesta compreensão e na organização e planejamento de sequências instrucionais. Um momento que foi significativo e importante, é a mudança na dinâmica do ambiente de aprendizagem, proporcionada pelas tarefas exploratórias, favorável às discussões matemáticas realizadas pelos alunos, conectando experiências, culturas, educação básica e os conteúdos do ensino superior, desta forma, dando o protagonismo a eles.

$\mathrm{Na}$ formulação de conjecturas específicas, os alunos usam, com frequência, raciocínio indutivo baseado na identificação de padrões através da observação de dados ou construindo os seus próprios esquemas visuais ou numéricos que desempenham uma dupla função de compreensão e de registo. No entanto, como seria de esperar, eles também usaram o raciocínio dedutivo baseado em definições e propriedades matemáticas utilizando representação algébrica para formularem conjecturas. Neste caso, a representação algébrica é usada como ferramenta de exploração e de apresentação de conjecturas e justificações formais.

A utilização da linguagem informal para produzir argumentos aceitáveis para validar conjecturas também parece ser mais fácil, para os alunos, quando comparada com o modo algébrico de representação.

Os resultados deste estudo evidenciam que os alunos, envolvidos neste estudo, usam tanto o raciocínio indutivo como dedutivo, mas que é necessário dar atenção a alguns processos de raciocínio em que se verificaram maiores dificuldades, como a generalização e a justificação, que estão menos presentes em seu trabalho.

Durante o desenvolvimento das TEDAEs, foi possível aprofundar estudos, documentar os processos de raciocínio, apoiar as aprendizagens que se aproximem da prática para a elaboração de estratégias para ações que envolvam o desenvolvimento do raciocínio, argumentação e prova que são considerados o cerne da atividade matemática, desempenhando um papel crucial nos processos de aprendizagem em todos os níveis, com atividades de cunho investigativo e exploratório para o contexto das horas de prática como componente curricular bem como a gestão de todo o currículo de matemática, dos cursos de Licenciaturas em Matemática. 


\section{Referências Bibliográficas}

BALL, David K., \& COHEN, Deborah L. Developing practice, developing practitioners: Toward a practice-based theory of professional education. In L. Darling-Hammond \& G. Sykes (Eds.), Teaching as the learning profession (pp. 3-32). San Francisco, CA: Jossey-Bass, 1999.

BOGDAN, Robert; BIKLEN, Sari. Investigação qualitativa em educação: Uma introdução à teoria e aos métodos. Porto: Porto Editora, 1994.

BRASIL. Base Nacional Comum Curricular: Educação Infantil e Ensino Fundamental. Brasília: MEC/Secretaria de Educação Básica, 2017.

COBB, Paul et al. Design Experiments in Education Research. Educational Researcher. V.32, no. 1, p. 9-13, jan/fev. 2003.

COBB, Paul \& Jackson, Kara. Analyzing Educational Policies: A Learning Design Perspective. The Journal of the Learning Sciences, 21:4, p. 487-521, 2012

COCHRAN-SMITH, Marylin. e LYTLE, Susan. L. (1999) Relationships of knowlegde of practice: teacher learning in communities. Review of Research in Education, 24, p.249-305.

Conselho Nacional de Educação. Define as Diretrizes Curriculares Nacionais para a Formação inicial em nível superior e para a formação continuada. Resolução CNE/CP No. 2, de 1o. de julho de 2015 b.

ERICKSON, Frederick. Qualitative methods in research on teaching. In: Wittrick, M. C.(org.). Handbook of research on teaching. New York: Macmillan, 1986, p. 119-161.

GATTI, Bernadette A. Didática e Formação de professores: provocações. Cadernos de Pesquisa, v. 47, n.166, out./dez. 2017, p. 1150-1164.

HENRIQUES, Ana. O pensamento matemático avançado e a aprendizagem da Análise Numérica num contexto de atividades de investigação. Portugal: UL, 2011, 462p. Tese (Doutorado) - Programa de Pós-Graduação em Didática da Matemática, Instituto de Educação, Universidade de Lisboa, 2011.

LIU, Yatin (2013). Aspects of mathematical arguments that influence eight grade students' judgment of their validity. EUA: Ohio State University, 2013, 307p. Tese (Doutorado) - Graduate Program in Education, Ohio State University, 2013.

MARCATTO, Flávia Sueli Fabiani. Prática como Componente Curricular: contribuições para a reflexão na Licenciatura em Matemática. Argumentos Pró-Educação. Pouso Alegre, MG, v. 4, n. 10, p. 731-754, jan.- abr., 2019.

MARCATTO, Flávia Sueli Fabiani. A prática como componente curricular em projetos pedagógicos de cursos de licenciatura em matemática. Brasil: UNESP, 2012, 174p. Tese (Doutorado). Programa de Pós-Graduação da Educação Matemática, Universidade Estadual Paulista, Rio Claro, 2012.

MATA-PEREIRA, Joana; PONTE, João Pedro da. Promover o Raciocínio Matemático dos Alunos: uma investigação baseada em design. Bolema. Rio Claro, SP, v. 32, n. 62, p. 781-801, dez. 2018. 
MATA-PEREIRA, Joana, \& PONTE, João Pedro da. Raciocínio matemático em conjuntos numéricos: Uma investigação no 3. ${ }^{\circ}$ ciclo. Quadrante, 21(2), 81-110, 2012.

MATA-PEREIRA, Joana; PONTE, João Pedro da. Teacher's Actions to Promote Students' Justifications. Acta Scientiae, Canoas, RS, v. 20, no. 3, p. 487-505, maio/jun. 2018.

NCTM. Princípios e normas para a Matemática escolar. Lisboa: APM, 2007. (Tradução portuguesa da edição original de 2000).

OLIVEIRA, Paulo. O raciocínio matemático à luz de uma epistemologia. Educação e Matemática, Lisboa, 100, p. 3-9, 2008.

PONTE, João Pedro da. Gestão curricular em Matemática. In GTI (Ed.), O professor $e$ o desenvolvimento curricular (pp. 11-34). Lisboa: APM, 2005.

PONTE, João Pedro da; CHAPMAN, Olive. Prospective mathematics teachers learning and knowledge for teaching. In L. English \& D. Kirshner (Eds.), Handbook of international research in mathematics education. New York, NY: Routledge/Taylor \& Francis, pp. 223-261, 2016.

PONTE, João Pedro da; MATA-PEREIRA, Joana; QUARESMA, Marisa. Ações do professor na condução de discussões matemáticas. Quadrante. V. 22, no. 2, pp. 55-81, 2013.

PONTE, João Pedro da; QUARESMA, Marisa. Representações e raciocínio matemático dos alunos na resolução de tarefas envolvendo números racionais numa abordagem exploratória.

Unipluri/versidad. V. 14, no. 1, pp.102-114, 2014.

PONTE, João Pedro da; MATA-PEREIRA, Joana; HENRIQUES, Ana. O raciocínio matemático nos alunos do ensino básico e do ensino superior. Práxis Educativa, Ponta Grossa, PR, v. 7, n. 2, 2012.

PONTE, João Pedro da et al. Perspectivas Teóricas no Estudo das Práticas Profissionais dos Professores de Matemática. Práticas de Ensino de Matemática. Lisboa, p. 267-278, 2012.

PREDIGER, Susanne, GRAVEMEIJER, Koeno, CONFREY, Jere. Design research with a focus on learning processes: an overview on achievements and challenges. ZDM, September, 47(6), p. 877$891,2015$.

ROLDÃO, M. do C. Conhecimento, Didática e Compromisso: o triângulo virtuoso de uma profissionalidade em risco. Cadernos de Pesquisa, v. 47, n. 166, p. 1134-1149, 2017.

SKOVSMOSE, Ole, PENTEADO, Miriam G. Mathematics Education an Democracy: An Open Landscape of Tensions, Uncertainties and Challeges. Handbook of International Research in Mathematics Education. By. Lyn D. English. David Kirshner, p.792-825, 2016.

STAPLES, Megan, Supporting Student Justification in Middle School Mathematics Classrooms: Teachers' Work to Create a Context for Justificaiton, 2014. CRME Publications. Disponível em: < http://digitalcommons.uconn.edu/merg_docs/4>. Acesso em: 10 out. 2018.

STYLIANIDES, Andreas J. e HAREL, Guershon. Advances in mathematics education research on proof and proving: An international perspective. Springer, 2018. 